\title{
Designation of Type Strains for Bifidobacterium Species
}

\author{
G. REUTER
}

Institute for Food Hygiene, Free University, Berlin-Dahlem, Germany

In 1963, the author described seven new species in the genus Bifidobacterium Orla-Jensen. However, type strains were not designated for these species, and therefore they are here established as follows: Bifidobacterium adolescentis $(\mathrm{E} 194 \mathrm{a}=\mathrm{ATCC} 15703), B$. breve $(\mathrm{S} 1=$ ATCC 15700), B. infantis (S12 = ATCC 15697), B. lactentis $(659=$ ATCC 25962), B. liberorum $(\mathrm{S} 76 \mathrm{e}=\mathrm{ATCC} 15702)$, B. longum $(\mathrm{E} 194 \mathrm{~b}=\mathrm{ATCC}$ 15707 ), and $B$. parvulorum (S50 = ATCC 15698). Descriptions of the type strains are given.

In 1963, microbiological investigations (3) of the stools of infants and adults resulted in the proposal of seven new species of the genus Bifidobacterium Orla-Jensen (2). However, at that time type strains were not designated for these species. In accordance with Rule 9a of the Bacteriological Code (1), type strains are here designated for these organisms.

\section{MATERIALS AND METHODS}

Bacterial strains. The organisms reported in this paper were isolated by the author or by J. Dehnert (strain 659) from the sources indicated in Table 1.

Methods. The media and methods used to characterize the type strains were described previously (3).

\section{RESULTS}

The strains cited in Table 1 were included among those on which the original descriptions of the species with which the strains are associated were based (3). These strains are here designated as the types of the species as indicated in Table 1, wherein the strains are described, and have been deposited in the American Type Culture Collection, Rockville, Md.

\section{LITERATURE CITED}

1. International Code of Nomenclature. 1966. Int. J. Syst. Bacteriol. 16(4):459-490.

2. Orla-Jensen, S. 1924. La classification des bactéries lactiques. Lait 4:468-474.

3. Reuter, G. 1963. Vergleichende Untersuchungen über die Bifidus-Flora im Säuglings- und Erwachsenstuhl. Zentralbl. Bakteriol. Parasitenk. Abt. I Orig. 191:486-507. 
TABLE 1. Descriptions of type strains of Bifidobacterium species

\begin{tabular}{|c|c|c|c|c|c|c|c|}
\hline $\begin{array}{c}\text { Species } \\
\text { Type strain } \\
\text { Source of type strain }\end{array}$ & \begin{tabular}{|c} 
B. adolescentis \\
Reuter \\
ATCC 15703 \\
(Reuter E194a) \\
Intestine of adult
\end{tabular} & $\begin{array}{l}\text { B. breve Reuter } \\
\text { ATCC } 15700 \\
\text { (Reuter S1) } \\
\text { Intestine of infant }\end{array}$ & $\begin{array}{l}\text { B. infantis Reuter } \\
\text { ATCC 15697 } \\
\text { (Reuter S12) } \\
\text { Intestine of infant }\end{array}$ & $\begin{array}{l}\text { B. lactentis Reuter } \\
\text { ATCC 25962 } \\
\text { (Dehnert 659) } \\
\text { Intestine of infant }\end{array}$ & $\begin{array}{c}\text { B. liberorum } \\
\text { Reuter } \\
\text { ATCC } 15702 \\
\text { (Reuter S76e) } \\
\text { Intestine of infant }\end{array}$ & $\begin{array}{l}\text { B. longum Reuter } \\
\text { ATCC 15707 } \\
\text { (Reuter E194b) } \\
\text { Intestine of adult }\end{array}$ & $\begin{array}{l}\text { B. parvulorum } \\
\text { Reuter } \\
\text { ATCC 15698 } \\
\text { (Reuter S50) } \\
\text { Intestine of infant }\end{array}$ \\
\hline Morphology & $\begin{array}{l}\text { Short, curved } \\
\text { rods which may } \\
\text { be bifurcated }\end{array}$ & $\begin{array}{l}\text { Very short, slen- } \\
\text { der, club-shaped } \\
\text { rods which may } \\
\text { be bifurcated }\end{array}$ & $\begin{array}{l}\text { Short, often swol- } \\
\text { len rods without } \\
\text { bifurcations }\end{array}$ & $\begin{array}{l}\text { Slender rods with- } \\
\text { out bifurcations }\end{array}$ & $\begin{array}{l}\text { Long, slender or } \\
\text { swollen rods with- } \\
\text { out bifurcations }\end{array}$ & $\begin{array}{l}\text { Long, curved, club- } \\
\text { shaped, swollen or } \\
\text { dumb-bell shaped } \\
\text { rods which may be } \\
\text { bifurcated }\end{array}$ & $\begin{array}{l}\text { Short, stout rods } \\
\text { without bifurcations }\end{array}$ \\
\hline Gram reaction & + & + & $\begin{array}{l}+ \\
\text { (granule frequently } \\
\text { in center of cell) }\end{array}$ & $\begin{array}{l}+ \\
\text { (granule frequently } \\
\text { in center of cell) }\end{array}$ & $\stackrel{+}{+}$ & $\begin{array}{c}+ \\
(\text { Gram-variable })\end{array}$ & $\begin{array}{c}+ \\
\text { (granular) }\end{array}$ \\
\hline Endospore & - & - & - & - & - & - & - \\
\hline Capsule & - & - & - & - & - & + & - \\
\hline Motility & - & - & - & - & - & - & - \\
\hline Colonies & $\begin{array}{l}\text { Convex to pulvi- } \\
\text { nate, entire, } 2-3 \\
\text { mm in diameter, } \\
\text { soft or paste- } \\
\text { like consistency }\end{array}$ & $\begin{array}{l}\text { Convex to pulvi- } \\
\text { nate, smooth or } \\
\text { undulating sur- } \\
\text { face, entire } 2-3 \\
\text { mm in diameter, } \\
\text { paste-like } \\
\text { consistency }\end{array}$ & $\begin{array}{l}\text { Convex to pulvi- } \\
\text { nate, entire, } 2-3 \\
\text { mm in diameter, } \\
\text { soft, moist or } \\
\text { paste-like con- } \\
\text { sistency }\end{array}$ & $\begin{array}{l}\text { Convex to pulvi- } \\
\text { nate, entire, } 2-3 \\
\text { mm in diameter, } \\
\text { soft, moist, } \\
\text { shining }\end{array}$ & $\begin{array}{l}\text { Convex to pulvi- } \\
\text { nate, entire, } 2-3 \\
\text { mm in diameter, } \\
\text { soft or paste- } \\
\text { like consistency }\end{array}$ & $\begin{array}{l}\text { Convex to pulvi- } \\
\text { nate, entire, } 2-5 \\
\mathrm{~mm} \text { in diameter, } \\
\text { soft, moist, shin- } \\
\text { ing or slimy }\end{array}$ & $\begin{array}{l}\text { Convex to pulvi- } \\
\text { nate, entire, } 2-3 \\
\mathrm{~mm} \text { in diameter, } \\
\text { soft or paste- } \\
\text { like consistency }\end{array}$ \\
\hline $\begin{array}{l}\text { Dispersion in } \mathrm{NaCl} \\
\text { solution }\end{array}$ & Homogenous & Agglutinating & Homogenous & Homogenous & Homogenous & Homogenous & Agglutinating \\
\hline Anaerobic & + & + & + & + & + & + & + \\
\hline $\begin{array}{l}\text { Growth in liquid } \\
\text { media without } \\
\text { added reducing } \\
\text { substances }\end{array}$ & - & $(+)$ & $(+)$ & - & - & $(+)$ & $(+)$ \\
\hline Catalase & - & - & - & - & - & - & - \\
\hline $\begin{array}{l}\text { Nitratase } \\
\text { Carbohydrate } \\
\text { fermentation } \\
\text { products: }\end{array}$ & - & - & - & - & - & - & - \\
\hline
\end{tabular}




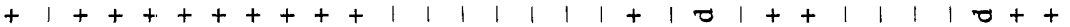

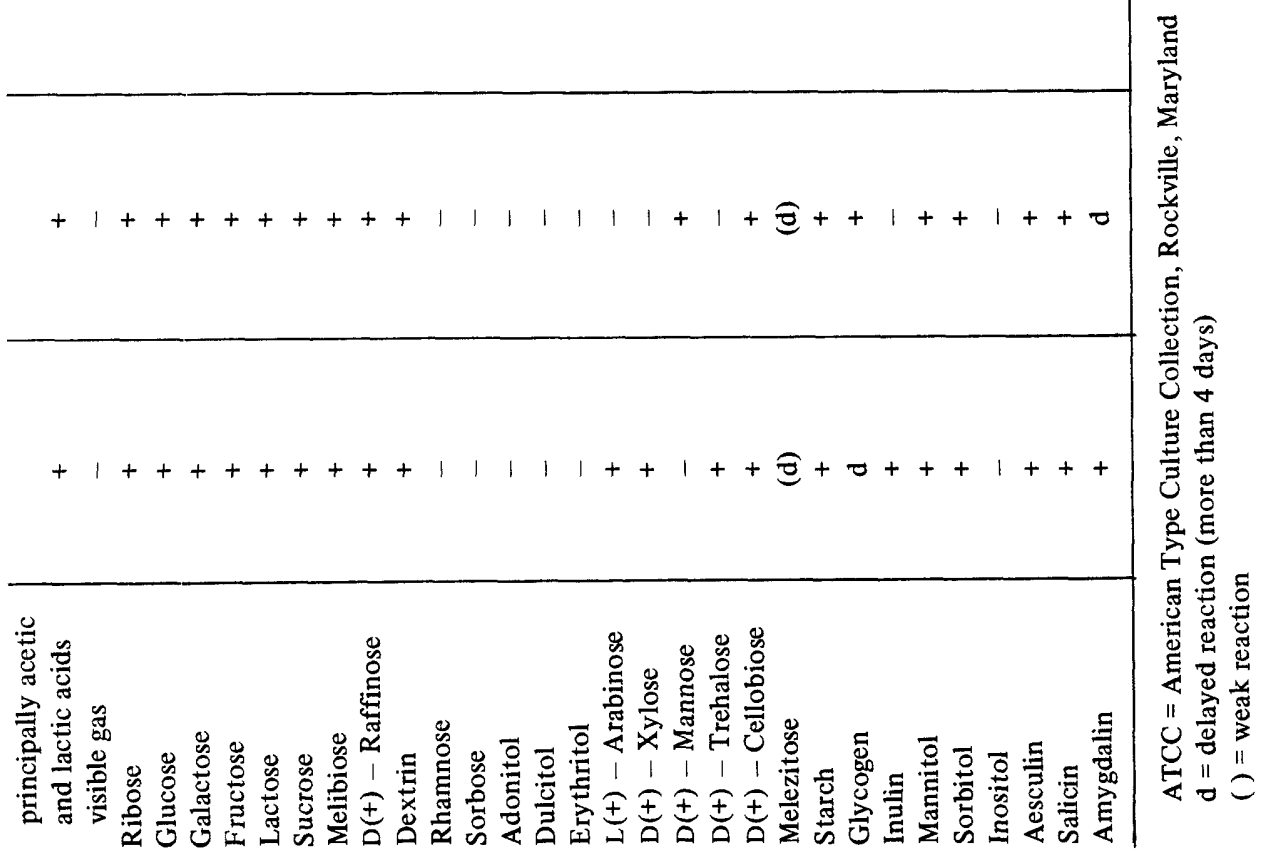

